\title{
Predicting Pain Catastrophizing of Women with Breast Cancer Based on Perceived Injustice and Past Time Perspective
}

\author{
Susan Alizadeh-Fard (i) ${ }^{1, *}$ \\ ${ }^{1}$ Payame Noor University, Tehran, Iran \\ "Corresponding author: Payame Noor University, Tehran, Iran. Email: salizadehfard@gmail.com
}

Received 2019 October 17; Revised 2020 February 23; Accepted 2020 March 03.

\begin{abstract}
Background: Pain experience is still the most important problem in women with breast cancer that could lead to psychological problems. There is notable literature that revealed perceived injustice, time perspective, and pain catastrophizing are associated with the same psychological variables and health-related behaviors.

Objectives: This study aimed at predicting pain catastrophizing based on a perceived injustice and past time perspective in women with breast cancer.

Methods: The present study was descriptive-correlational in terms of method. The statistical population consisted of all women aged 20 to 50 years with a breast cancer diagnosis in 5 hospitals in Tehran, Iran (Emam Khomeini, Hazraterasol, Mohebmehr, Shahram, and Khatam). A total of 142 voluntary patients were selected through the available sampling method. The instruments of the study included the Zimbardo Time Perspective Inventory (ZTIP), The Injustice Experiences questionnaire (IEQ), and the Pain Catastrophizing scale (PCS). The data was analyzed, using Pearson correlation and step by step regression and path analysis.

Results: The results showed that perceived injustice, past negative, and past positive had a significant relationship with pain catastrophizing. The perceived injustice, past negative, explained approximately $72 \%$ of the variance of pain catastrophizing. Also, perceived injustice is a mediator variable between past negative and pain catastrophizing.

Conclusions: Overall, the results of this study support the role of past negative time perspective and perceived injustice in predicting pain catastrophizing in women with breast cancer. Since pain is experienced in a complex social and cultural milieu, there is a great value for identifying variables that might mitigate or exacerbate perceived pain and could contribute greatly to the development of more effective psychosocial treatments. Therefore, dealing with past negative time perspective and perceived injustice can prevent pain catastrophizing and, consequently, perceived pain and its intensity could be decreased.
\end{abstract}

Keywords: Pain Catastrophizing, Perceived Injustice, Past Time Perspective, Breast Cancer, Women

\section{Background}

Breast cancer is the most common malignancy of women around the world that has more severe mental and emotional effects than other types (1). Despite recent improvements in pharmacological treatment, pain experience is still the most important problem affecting patients' lifestyle (2), and the complete relief of pain is rare (3).

Recently in pain studies, it is suggested to use a biopsychosocial (4) somatic, cognitive, emotional, behavioral, social, and motivational (SCEBSM) model. The cognitive factor in this model means cognitive patterns in perception and making sense of pain. The most important cognitive patterns are catastrophizing, perceived injustice, and time perspective (5).

Pain catastrophizing is the tendency to negative thought style in response to pain, which is characterized by exaggerating the minatory meaning of pain (6) and a cognitive pattern that individuals show to focus on cognitive threatening cues to making sense of their pain. This cognitive pattern amplifies the negative value of pain and decreased ability to control pain (7).

Social psychology suggests that we have a basic abomination to injustice and belief in just world: "individuals need to believe they live in a world, in which each person gets what he deserves and deserves what he gets, whether good or bad" (8). Health psychology research suggests that individuals' beliefs in justice can affect their health outcomes (9). Perceived injustice in health and illness has been operationally defined as: "a cognitive appraisal comprising elements of the exaggerated severity of loss consequent to injury or pain onset, perceived irreparability of loss, a sense of unfairness, and blame" (10). Research has 
shown that some psychological factors such as depression (11-13), anxiety (12), psychological distress (14), and personality traits like the lack of self-esteem (15), pessimism (16), neuroticism (15), and external locus of control (15), as well as social factors like social disability (17), decrease income $(11,18)$, and even social class (18) can lead to the perceptions of injustice in patients.

Time perspective shows the individual's method regarding psychological notions of past, present, and future (19). It was defined as a stable unconscious process determined by circumstances, through which the personal and social experiences are allocated to time frames. These frames have significant impacts on individuals' cognitions and actions. The impact of the time perspective on psychological well-being (20), subjective well-being (21), anxiety (22), and depression (23) has been broadly investigated. The findings of time perspective in a patient with cancer indicate that past negative and present-fatalistic scores have a high relationship with distress, depression, anxiety, and aggression in these patients (24). Another research found that scores of future and past-positive are more than others (25). Other studies showed past-negative is related to depression (26). Also, present fatalists are negatively and the future is positively related to physical activity in the patient with cancer (27).

As was previously mentioned, the most important cognitive patterns are catastrophizing, perceived injustice, and time perspective (5). The association of these variables has been studied in previous studies. Studies have shown past-negative is correlated with pain catastrophizing (28). More recently researchers have found that all factors of pain catastrophizing (rumination, helplessness, and magnification) have positive correlations with the past-negative (29). On the other hand, it has been made clear that pain catastrophizing has a positive correlation with the perceived injustice (30). It is indicated that catastrophizing mediates the relationship between personal belief in a just world and pain outcomes in chronic pain (9).

Theoretical explanation as to why pain catastrophizing correlated with perceived injustice and past time perspective relates to two psychological models. The first one is the attention bias model (31). In this model, past negative and injustice beliefs are considered a dysfunctional bias of attention toward negative events. This model addresses why and how maladaptive attention interrupted to a state of cognitive and behavioral immobilization (31).

The second model is the schema-activation model of Sullivan et al. $(6,32)$ that proposed that past negative and injustice beliefs possess special schema, which consisted of a distorted cognition with excessively pessimistic beliefs about negative experiences and actual ability to cope (33).

Despite acknowledging these results, still, two points have remained. First, although the relationship between time perspective and perceived injustice with pain catastrophizing has been investigated and the relationship of these 3 variables with each other has not yet been studied. Second, most of the research has not focused on cancer.

\section{Objectives}

Therefore, considering these points led us to two hypotheses: (1) Pain catastrophizing would be correlated with the perceived injustice and past time perspective; (2) the perceived injustice and past time perspective can predict pain catastrophizing in women with breast cancer.

\section{Methods}

The present study was descriptive-correlational in terms of method. The statistical population consisted of all women aged 20 to 50 years with a breast cancer diagnosis in 5 hospitals in Tehran, Iran (Emam Khomeini, Hazraterasol, Mohebmehr, Shahram, and Khatam). The number of patients with breast cancer in these hospitals was 219, which required at least 140 samples were selected according to the Krejcie and Morgan So, So, 142 voluntary female subjects were selected through the available sampling method between March and April 2019.

In each hospital, patients with breast cancer, who met the inclusion criteria, were initially identified. Then, the research method and how to use the results based on ethical considerations were explained verbally. The written informed consent was taken from all participants and the Payame Noor University board of ethics approved the protocol of the study. If they agreed, they would complete questionnaires in the presence of the researcher. This was done by frequent visits to these 5 hospitals.

The inclusion criteria included the diagnosis of breast cancer by specialists at least 6 months and the utmost 1 year before the onset of the study, getting chemotherapy, age between 20 and 50 years, at least educated as diploma, and consent to participate in the research. Ethical issues including informed consent, right to withdraw from research, confidentiality, respect for privacy, considering plagiarism, data fabrication and/or falsification, double publication and/or submission, and redundancy have been completely observed by the author. After selecting the sample, the questionnaires were completed by the participants with the supervision of the researcher. Then results were analyzed through the regression and path analysis method by SPSS-19 and AMOS-22. 


\subsection{Measures}

\subsubsection{Injustice Experiences Questionnaire}

The Injustice Experiences questionnaire is a 12-item test that assesses pain-related perceptions of injustice (17). These pain-related items evaluate two correlated factors: severity/irreparability of loss and blame/unfairness. Each one is measured by a 5 -point Likert scale from 0 (never) to 4 (all the time). The Injustice Experiences questionnaire has high internal and test-retest reliability and it is valid among English, French, and Persian-speaking individuals $(17,34)$. Cronbach's alpha was 0.82 in the present study.

\subsubsection{Zimbardo Time Perspective Inventory}

The Zimbardo Time Perspective Inventory is a 36-item scale developed to evaluate different focused of time perspective (22). It assesses 5 components of time perspective. Items are only related to the past (past positive 7 items and past negative 9 items). Each dimension is measured by a 5-point Likert scale from 1 (absolutely untrue) to 5 (absolutely true). Studies provided support for the internal consistency, stability, and structural validity of this scale (35). Cronbach's alpha of past positive and past negative were 0.78 and 0.83 , respectively, in the present study.

\subsubsection{Pain Catastrophizing}

The Pain Catastrophizing scale is a 13-item measure that was developed and validated by Sullivan et al. (32). These items are rated on a 5-point Likert scale from 0 (never) to 6 (always). This test is a reliable and valid measure and a high internal consistency (11). Also, it has suitable reliability and validity in the Iranian population (36). Cronbach's alpha was 0.86 in the present study.

\section{Results}

First of all, the characteristics of the samples are shown in Table 1.

\begin{tabular}{lc}
\hline Table 1. Characteristics of the Participants ${ }^{\mathrm{a}}$ & \\
\hline Variables & Values \\
\hline Age & $42.18 \pm 7.64$ \\
Married & $82(58)$ \\
Time of diagnosis, mo & $10.03 \pm 0.08$ \\
\hline${ }^{\mathrm{a}}$.
\end{tabular}

The mean and standard deviation \pm SD of participants' scores of research variables are shown in Table 2.

For analyzing the correlation among all variables, the Pearson test was used. These results are illustrated in Table 3.

\begin{tabular}{lc}
\hline \multicolumn{2}{l}{ Table 2. The Mean and Standard Deviation of the Participants ${ }^{\mathrm{a}}$} \\
\hline Variables & Values \\
\hline PI & $25.72 \pm 10.7$ \\
PN & $27.16 \pm 5.7$ \\
PP & $21.49 \pm 4.3$ \\
PC & $3.82 \pm 0.46$ \\
\hline
\end{tabular}

Abbreviations: PC, pain catastrophizing; PN, past negative; PP, past positive; PI, perceived injustice.

${ }^{\text {a }}$ Values are expressed as mean $\pm \mathrm{SD}$.

In line with results shown in Table 3, PC is significantly correlated with PI, PN, and PP.Also, there is a significant correlation between $\mathrm{PI}$ and $\mathrm{PN}$.

A step by step regression analysis was used to test whether past time perspective and perceived injustice were associated with pain catastrophizing. The results are illustrated in Table 4.

According to Table 4, both models in the first and second steps are significantly meaningful, and the second model can explain more total changes of PC in comparison with the first one (72\% is more than $67 \%$ ).

Also, in the first step, only PN entered into the equation and PN and PI entered into the equation in the next step. The $\beta$ of IP is 0.46 that means IP can predict $46 \%$ of PC. The $\beta$ of PN in the first step is 0.31 and decreases in the next step to 0.19 that means although PN can predict PC directly, PI is a mediator variable between PN and PC.

The strength of direct and indirect links between variables is indicated by the path analysis. These results are in Table 5 and Figure 1.

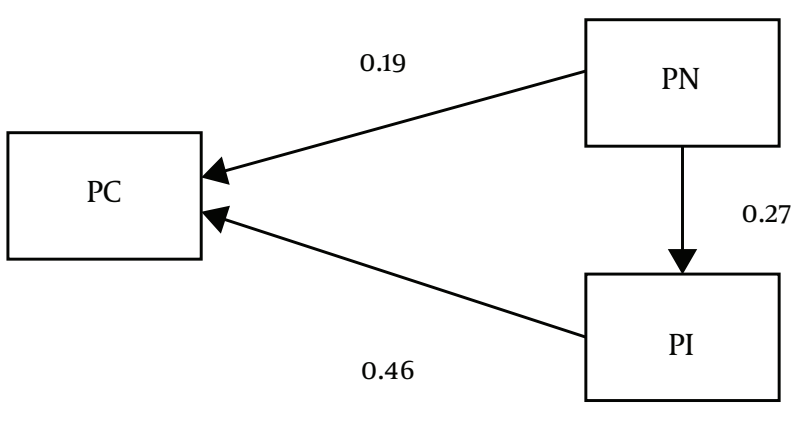

Figure 1. The final model of the relationship between variables

\section{Discussion}

As was previously mentioned, in the SCEBSM model of pain study, different biopsychosocial factors are involved 


\begin{tabular}{|c|c|c|c|c|c|c|c|}
\hline & & $\mathbf{1}$ & 2 & 3 & & 4 & \\
\hline 1. PI & & 1.00 & & & & & \\
\hline 2. PN & & $0.43^{\mathrm{a}}$ & 1.00 & & & & \\
\hline 3. PP & & -0.11 & $-0.19^{\mathrm{b}}$ & 1.00 & & & \\
\hline 4. $\mathrm{PC}$ & & $0.68^{\mathrm{a}}$ & $0.38^{\mathrm{b}}$ & $-0.27^{b}$ & & 1.00 & \\
\hline \multicolumn{8}{|c|}{$\begin{array}{l}\text { Abbreviations: PC, pain catastrophizing; PN, past negative; PP, past positive; PI, perceived injustice. } \\
{ }^{\mathrm{a}} \mathrm{P} \leq 0.001 \text {. } \\
{ }^{\mathrm{b}} \mathrm{P} \leq 0.01 .\end{array}$} \\
\hline & Variables & $\mathbf{R}$ & $\mathrm{R}^{2}$ & $\mathbf{F}$ & B & $\beta$ & $\mathbf{P}$ \\
\hline 1 Step & PN & 0.81 & 0.67 & $107.65^{\mathrm{a}}$ & 2.806 & 0.31 & 0.01 \\
\hline \multirow{2}{*}{2 Step } & PN & \multirow{2}{*}{0.84} & \multirow{2}{*}{0.72} & \multirow{2}{*}{$108.31^{\mathrm{a}}$} & 3.371 & 0.19 & 0.001 \\
\hline & PI & & & & 4.239 & 0.46 & 0.001 \\
\hline
\end{tabular}

Abbreviations: PC, pain catastrophizing; PN, past negative; PI, perceived injustice. ${ }^{\mathrm{a}} \mathrm{P} \leq 0.001$.

Table 5. Regression Coefficient and P Value of the Final Model

\begin{tabular}{lcc}
\hline Link & Regression Coefficient & P \\
\hline PI $\rightarrow$ PC & 0.46 & 0.001 (Direct) \\
PN $\rightarrow$ PC & 0.19 & 0.01 (Direct) \\
$\mathbf{P N ~} \rightarrow$ PI $\rightarrow$ PC & 0.27 & 0.001 (Indirect) \\
\hline
\end{tabular}

and the most important cognitive factors are catastrophizing, perceived injustice, and time perspective. The aim of this study was to investigate the relationship between these cognitive patterns and whether perceived injustice and past time perspectives are correlated with pain catastrophizing and could predict it.

The findings indicated a significant correlation between pain catastrophizing with past positive (negatively) and past negative (positively) and perceived injustice. These results are similar to other studies that showed pastnegative and past-positive correlated with pain catastrophizing $(5,28,29)$. Likewise, the results are consistent and comparable with findings in previous investigations concerning the relationship between pain catastrophizing and perceived injustice $(9,30)$. But, the difference is that they are not about breast cancer and were conducted generally on pain or chronic pain.

Another important finding from the regression and path analysis indicated that past negative can predict pain catastrophizing both directly and indirectly through mediating perceived injustice.

The same theoretical models will be used to describe these results. Based on the attention bias model (31) and schema-activation model $(6,32)$, past negative and injustice beliefs create a dysfunctional bias of attention toward negative events.

If these variables are studied in a SCEBSM model, it should be considered that cognitive functions cause to develop an autobiographical and episodic memory, selfrelated processing, and future imagine (32). This means that negative events shape negative memories and eventually lead to a dominant cognitive pattern for information processing. This cognitive pattern is a negative time perspective. When the prevailing perspective to the past is negative, these negative memories form an active negative schema, in which events are perceived.

The negative time perspective means focusing on events that are very powerful because they dominate all the past. Secondly, their effect remains until now because the individual could not overcome them and they were uncontrollable (32).

Under the influence of this schema, the experience of pain is considered a negative experience, just like other negative memories in the past. So, the characteristics of those memories are also attributed to this current pain experience. Thus, the experience of pain will be perceived in this pattern and processed as a ruminate, helpless, and magnificent event. In other words, it will lead to pain catastrophizing (33).

On the other hand, it is important to note that one of the most important components of cognitive processing is attention. There are many stimuli around at any given moment, but only some of them are considered. When negative memories are dominant cognitive patterns, they cause 
salience and attention bias to negative. This attention bias leads to perceiving more negative events. Life will be filled with negative experiences. This leads to a sense of injustice. One has to ask why all of my life experiences are negative and frustrating. As a result, the negative past perspective leads to a perception of injustice (31).

Injustice perception of pain has different dimensions. One of them is the disability. In an injustice world, pain is the result of injustice destiny. Not only the individuals have no role in causing pain, but also they cannot control it. Besides, instead of using pain management and coping techniques, some reactions like anger, revenge, and blame are used. These negative reactions increase negative emotions such as depression and frustration, and they are associated with more perception of pain intensity and severity. Therefore, more perceived pain severity and inability will lead to pain catastrophizing (33).

\subsection{Conclusions}

Overall, the present study showed a significant positive correlation between pain catastrophizing with perceived injustice and past negative and negatively with past positive. Also, the results of the current study indicated that perceived injustice and past negative time perspective can predict pain catastrophizing.

\subsection{Limitations}

The present study has some limitations. First, the participants of this research were volunteers and chosen from some hospitals in Tehran; thus, they may not be representative of the target population. Besides, the patients, who accepted to participate, have a different type of socioeconomic status. Therefore, the influence of social status type should be considered. The third limitation is about the relationship between pain intensity and research variables that were not investigated. Also, due to the exploratory nature of the study, we could not ascertain the mechanism, through which perceived injustice and past negative time perspectives influenced catastrophizing in patients with breast cancer.

These limitations suggest that future research should address these issues by a qualitative study or by using mixed methods. We also hope that the results of this study will lead to the development of interventions aimed at controlling and balancing negative time perspective and injustice pain experiences to reduce pain disaster.

\section{Acknowledgments}

We would like to thank all the patients and managers of the hospitals, who contributed to this study.

\section{Footnotes}

Authors' Contribution: None declared.

Conflict of Interests: There is no conflict of interest.

Ethical Approval: The Payame Noor University Board of Ethics approved the protocol of the study.

Funding/Support: This study was not supported by any funding.

Informed Consent: The written informed consent was taken from all participants.

\section{References}

1. Sharif Nia H, Pahlevan Sharif S, Lehto RH, Boyle C, Yaghoobzadeh A, Kaveh O, et al. Development and psychometric evaluation of a Persian version of the Death Depression Scale-Revised: A crosscultural adaptation for patients with advanced cancer.Jpn JClin Oncol. 2017;47(8):713-9. doi: 10.1093/jjco/hyx065. [PubMed: 28505271].

2. Badr H, Shen MJ. Pain catastrophizing, pain intensity, and dyadic adjustment influence patient and partner depression in metastatic breast cancer. Clin J Pain. 2014;30(11):923-33. doi: 10.1097/AJP.0000000000000058. [PubMed: 24402001]. [PubMed Central: PMC4461876].

3. Zech DF, Grond S, Lynch J, Hertel D, Lehmann KA. Validation of World Health Organization Guidelines for cancer pain relief: A 10-year prospective study. Pain. 1995;63(1):65-76. doi: 10.1016/03043959(95)00017-m. [PubMed: 8577492].

4. Speckens AE, Van-Rood Y. Formal treatment of patients with unexplained physical symptoms: Cognitive behavioral therapy. In: Formal treatments in the ambulatory mental health care. Houten, Netherlands: Bohn Stafleu Van Loghum; 2004. p. 183-218.

5. Wijma AJ, van Wilgen CP, Meeus M, Nijs J. Clinical biopsychosocial physiotherapy assessment of patients with chronic pain: The first step in pain neuroscience education. Physiother Theory Pract. 2016;32(5):368-84. doi: 10.1080/09593985.2016.1194651. [PubMed: 27351769].

6. Sullivan MJ, Thorn B, Haythornthwaite JA, Keefe F, Martin M, Bradley LA, et al. Theoretical perspectives on the relation between catastrophizing and pain. Clin J Pain. 2001;17(1):52-64. doi: 10.1097/00002508200103000-00008. [PubMed: 11289089].

7. Quartana PJ, Campbell CM, Edwards RR. Pain catastrophizing: A critical review. Expert Rev Neurother. 2009;9(5):745-58. doi: 10.1586/ern.09.34. [PubMed: 19402782]. [PubMed Central: PMC2696024].

8. Nudelman G. The belief in a Just World and personality: A metaanalysis. Soc Justice Res. 2013;26(2):105-19. doi: 10.1007/s11211-013-0178y.

9. McParland JL, Knussen C. Catastrophizing mediates the relationship between the personal belief in a just world and pain outcomes among chronic pain support group attendees. Psychol Inj Law. 2016;9:23-30. doi: 10.1007/s12207-015-9246-y. [PubMed: 27053979]. [PubMed Central: PMC4781886].

10. Whitney CA, Dorfman CS, Shelby RA, Keefe FJ, Gandhi V, Somers TJ. Reminders of cancer risk and pain catastrophizing: Relationships with cancer worry and perceived risk in women with a first-degree relative with breast cancer. Fam Cancer. 2019;18(1):9-18. doi: 10.1007/s10689018-0082-6. [PubMed: 29679190]. [PubMed Central: PMC7028392].

11. Trost Z, Agtarap S, Scott W, Driver S, Guck A, Roden-Foreman K, et al. Perceived injustice after traumatic injury: Associations with pain, psychological distress, and quality of life outcomes 12 months after injury. Rehabil Psychol. 2015;60(3):213-21. doi: 10.1037/rep0000043. [PubMed: 26192050]. 
12. McParland JL, Knussen C, Murray J. The effects of a recalled injustice on the experience of experimentally induced pain and anxiety in relation to just-world beliefs. Eur J Pain. 2016;20(9):1392-401. doi: 10.1002/ejp.862. [PubMed: 26992062].

13. Scott W, Sullivan M. Perceived injustice moderates the relationship between pain and depressive symptoms among individuals with persistent musculoskeletal pain. Pain Res Manag. 2012;17(5):33540. doi: 10.1155/2012/501260. [PubMed: 23061084]. [PubMed Central: PMC3465094].

14. Paquet M, Bois K, Rosen NO, Mayrand MH, Charbonneau-Lefebvre V, Bergeron S. Why us? Perceived injustice is associated with more sexual and psychological distress in couples coping with genitopelvic pain. J Sex Med. 2016;13(1):79-87. doi: 10.1016/j.jsxm.2015.11.007. [PubMed: 26755090].

15. Zitny P, Halama P. Self-esteem, locus of control, and personality traits as predictors of sensitivity to injustice. Stud Psychol. 2011;53(1):27-40.

16. Hill EL. Expectations of fairness: The influence of pessimism on psychological and psychophysiological reactions to injustice. Sci Engin. 2000;61(4-B):2271.

17. Sullivan MJ, Adams H, Horan S, Maher D, Boland D, Gross R. The role of perceived injustice in the experience of chronic pain and disability: Scale development and validation. J Occup Rehabil. 2008;18(3):249-61. doi:10.1007/s10926-008-9140-5. [PubMed: 18536983].

18. Sturgeon JA, Carriere JS, Kao MJ, Rico T, Darnall BD, Mackey SC. Social disruption mediates the relationship between perceived injustice and anger in chronic pain: A collaborative health outcomes information registry study. Ann Behav Med. 2016;50(6):802-12. doi: 10.1007/s12160-016-9808-6. [PubMed: 27325314]. [PubMed Central: PMC5127748].

19. Boniwell I. Beyond time management: How the latest research on time perspective and perceived time use can assist clients with time-related concerns. Int J Evidence-Based Coaching Mentoring. 2005;3(2):61-74.

20. Zimbardo PG, Boyd JN. Putting time in perspective: A Valid, reliable individual-differences metric. In: Stolarski M, Fieulaine N, Beek WV, editors. Time perspective theory; Review, research and application. Gerany: Springer; 2015. p. 17-55. doi: 10.1007/978-3-319-07368-2_2.

21. Zambianchi M. Time perspective and psychological well-being in old age. BPA-Appl Psychol Bull. 2015;63(274).

22. Zhang JW, Howell RT, Stolarski M. Comparing three methods to measure a balanced time perspective: The relationship between a balanced time perspective and subjective well-being. J Happiness Stud. 2012;14(1):169-84. doi: 10.1007/s10902-012-9322-x.

23. Fieulaine N, Apostolidis T. Precariousness as a time horizon: How poverty and social insecurity shape individuals' time perspectives. Time perspective theory; review, research and application. Germany: Springer; 2015. p. 213-28. doi: 10.1007/978-3-319-07368-2_14.

24. Wakefield CE, Homewood J, Taylor A, Mahmut M, Meiser B. Time perspective in hereditary cancer: Psychometric properties of a short form of the zimbardo time perspective inventory in a community and clinical sample. Genet Test Mol Biomarkers. 2010;14(5):617-27. doi: 10.1089/gtmb.2009.0185. [PubMed: 20722497].

25. Nozari M, Janbabai G, Dousti Y. Time perspective in healthy individuals and patients suffering from cancer and diabetes. Ann Univ Paedagog Crac Stud Psychol. 2013;6:157-65.

26. Bitsko MJ, Stern M, Dillon R, Russell EC, Laver J. Happiness and time perspective as potential mediators of quality of life and depression in adolescent cancer. Pediatr Blood Cancer. 2008;50(3):613-9. doi: 10.1002/pbc.21337. [PubMed: 17879282].

27. Villaron C, Marqueste T, Eisinger F, Cappiello MA, Therme P, Cury F Links between personality, time perspective, and intention to practice physical activity during cancer treatment: An exploratory study. Psychooncology. 2017;26(4):531-6. doi: 10.1002/pon.4194. [PubMed: 27309735].

28. Sobol-Kwapinska M, Plotek W, Babel P, Cybulski M, Kluzik A, Krystianc J, et al. Time perspective as a predictor of acute postsurgical pain and coping with pain following abdominal surgery. Eur J Pain. 2017;21(4):635-44. doi:10.1002/ejp.967. [PubMed: 27734562].

29. Gács B, Birkás B, Csathó Á. Time perspectives and pain: Negative time perspective profile predicts elevated vulnerability to pain. Pers Individ Differ. 2020;153. doi:10.1016/j.paid.2019.109616.

30. Nijs J, Wijma AJ, Leysen L, Pas R, Willaert W, Hoelen W, et al. Explaining pain following cancer: A practical guide for clinicians. Braz JPhys Ther 2019;23(5):367-77. doi: 10.1016/j.bjpt.2018.12.003. [PubMed: 30606621]. [PubMed Central: PMC6823686].

31. Eccleston C, Crombez G. Pain demands attention: A cognitiveaffective model of the interruptive function of pain. Psychol Bull. 1999;125(3):356-66. doi: 10.1037/0033-2909.125.3.356. [PubMed: 10349356].

32. Sullivan MJL, Bishop SR, Pivik J. The pain catastrophizing scale: Development and validation. Psychol Assess. 1995;7(4):524-32. doi: 10.1037/1040-3590.7.4.524.

33. Leung L. Pain catastrophizing: An updated review. Indian J Psychol Med. 2012;34(3):204-17. doi: 10.4103/0253-7176.106012. [PubMed 23441031]. [PubMed Central: PMC3573569].

34. Rahbari A, Dehestani M, Baharlouei H. Psychometric characteristics of the Persian version of the injustice experience questionnaire. Psychol Inj Law. 2019;12(3-4):238-46. doi:10.1007/s12207-019-09344-y.

35. Alizadefard S, Mohtashami T, Hadhidhatgoo M, Zimbardo FG. [Investigation of psychometric characteristics of time perspective inventory (short form) in adult population of Tehran]. J Clin Psychol Pers. 2017;14(2):157-69. Persian.

36. Rahmati N, Asghari Moghadam MA, Shairi M, Paknejad M, Rahmati Z, Ghassami M, et al. A study of the psychometric properties of the pain catastrophizing scale amongst iranian patients with chronic persistent pain. J Ilam Univ Med Sci. 2017;25(1):63-79. doi: 10.29252/sjimu.25.1.63 